\title{
CHAT EDUCACIONAL NO ENSINO DE ESPANHOL EM AMBIENTE VIRTUAL
}

\section{EDUCATIONAL CHAT IN SPANISH TEACHING IN VIRTUAL ENVIRONMENT}

\section{Crisciene Lara Barbosa-Paiva*}

\begin{abstract}
RESUMO
Neste artigo, analisamos o chat educacional a partir da análise da construção composicional, dos conteúdos temáticos e da função em sessões de chat educacional dirigido ao ensino de espanhol como língua estrangeira para brasileiros. Verificamos a presença de cinco momentos, que constroem composicionalmente o gênero chat educacional. Houve a ocorrência de duas vertentes temáticas: a primeira, relacionada ao funcionamento, organização e realização de atividades do curso EPT e a segunda, ao conhecimento pessoal entre os participantes. No que tange à função, observamos que os participantes viam nele uma oportunidade de tirar as dúvidas com o professor ou com os colegas, conhecer melhor os participantes de curso ou praticar a língua estrangeira em contexto real de uso da linguagem.
\end{abstract}

Palavras-chave: Chat educacional; gênero digital; espanhol como língua estrangeira.

\section{ABSTRACT}

This study aimed at describing the educational chat based on the compositional construction analysis, on the theme content and on its function. Regarding the analysis of genre, we verified the presence of five moments, which compositionally construct the educational chat gender. As for the subject content, we found that there were two thematic components: the first one was related to the operation, organization and implementation of the activities of the course; and the second one, related to personal knowledge between the participants. Regarding the role of educational chat, during course, we observed that participants considered it as an opportunity to solve doubts with the teacher or with colleagues, learn more about the participants of the course or practicipate to a real context of foreign language use.

Keywords: Educational chat; Digital gender; Spanish as a foreign language.

\section{INTRODUÇÃO}

Neste artigo, analisamos o chat educacional a partir da análise da construção composicional, dos conteúdos temáticos e da função em sessões de

\footnotetext{
* Universidad de Salamanca, Salamanca, Espanha. crisbarbosa.paiva@gmail.com

Agradeço à Profa. Dra. Mercedes Marcos Sánchez, Professora Titular de Linguística do Departamento de Lengua Española, da Facultad de Filología da Universidad de Salamanca, Espanha, pela leitura atenciosa deste artigo. Agradeço também à CAPES e ao CNPq, pelos apoios financeiros recebidos.
} 
chat educacional realizadas, essencialmente, por escrito, em tempo real (sem o uso de recursos de áudio e vídeo), em língua estrangeira (no caso, o espanhol) por participantes brasileiros. Dessa forma, o presente artigo contribuirá para esclarecer o funcionamento de um dos gêneros de chat - o chat educacional, que está voltado para o ensino e aprendizagem de língua estrangeira (espanhol) em ambiente virtual. Acreditamos que a escolha dos elementos de análise (a construção composicional, a temática e a função), que propusemos analisar neste artigo, permite uma melhor compreensão de um novo gênero, que nasceu com as novas tecnologias de informação e comunicação e que pertence a um contexto em que, de acordo com Crystal (2005, p. 80), "as opções de comunicação do usuário são determinadas pela natureza do hardware necessário para se obter acesso à Internet. Assim, uma série de caracteres em um teclado determina a capacidade lingüística produtiva".

No que concerne à construção composicional, este trabalho, baseandose no que Araújo e Costa (2007) definem para o gênero de chat aberto, busca verificar como se constrói composicionalmente outro tipo de chat, o educacional. Partiremos da metodologia de análise que define os cinco momentos do chat aberto estudados por esses autores.

As sessões de chat que serão analisadas pertencem a um curso de espanhol com fins específicos, intitulado "Español para Turismo" (EPT), que foi oferecido como um curso de extensão universitária de 30 h, no ano de 2007, na Universidade Estadual Paulista "Júlio de Mesquita Filho" (UNESP - campus de Araraquara, São Paulo, Brasil). O programa de chat utilizado foi o da plataforma Moodle.

O EPT foi oferecido a quatro turmas, em duas modalidades diferentes: dois na modalidade semipresencial e dois na modalidade a distância, e para cada uma das turmas foi nomeado um docente responsável. Este trabalho utiliza somente os dados referentes às turmas ministradas na modalidade a distância que tiveram como docente responsável os professores Irene e Marcos (nomes fictícios). Cada curso foi realizado de forma independente um do outro, mas simultaneamente. O curso da Profa. Irene apresentou uma totalidade de 21 sessões de chats e teve 17 participantes (1 professora e 16 estudantes), já o curso do Prof. Marcos teve uma totalidade de 31 sessões e contou com 17 participantes (1 professor e 16 aprendizes). Todas essas sessões, relativas aos dois cursos, são analisadas neste trabalho. Cumpre esclarecer que, nos dois cursos, não eram todos os participantes que interagiam ao mesmo tempo em uma mesma sessão de chat.

O programa de chat fazia parte do curso EPT e integrava as ferramentas disponíveis na plataforma Moodle. O chat foi uma das atividades obrigatórias 
do curso. Com relação ao tratamento do corpus, esclarecemos que não foram realizadas alterações nos textos conversacionais, uma vez que, como afirma Marcuschi (2005, p. 63), trata-se de "uma linguagem em seu estado natural de produção". Acrescentamos que os dados pessoais, inscritos nas sessões de chat, foram trocados, a fim de preservar a identidade dos participantes.

\section{FUNDAMENTAÇÃO TEÓRICA}

\subsection{Chat - uma conversação síncrona escrita mediada por computador}

O chat tem sido definido de formas diferentes pela literatura. Diante desse contexto, Barbosa-Paiva (2010) propõe uma definição de chat que permita uma complementação entre essas definições, e não um caráter de exclusão. Assim, a autora entende por chat:

i) uma conversação escrita mediada por computador, que reflete as condições de produção ligadas ao tempo real ou on-line, ii) um novo gênero (digital), que apresenta características próprias que o singularizam e está submetido às condições de produção da informática e da conexão em rede, entre outros aspectos relacionados à tecnologia digital (BARBOSA-PAIVA, 2010, p. 49).

Barbosa-Paiva (2015, p. 19) salienta que o "chat educacional pertence, assim, ao conjunto de gêneros que compõem a Ciberfala - as comunicações da internet. Esse gênero digital é, portanto, uma das formas de interação da Ciberfala". Além disso, o chat educacional é um dos gêneros que constituem a "constelação de gêneros chats" (ARAÚJO, 2006), isto é, há vários gêneros de chat, os quais apresentam diversos propósitos comunicativos (ARAÚJO, 2006). Entre os gêneros chat, a autora cita: Chat Aberto, Chat Reservado, Chat Agendado, Chat de Atendimento (ao Assinante), entre outros.

Vejamos no Quadro (1), no que diz respeito à temática, a comparação de Barbosa-Paiva (2015) entre o chat aberto', investigado por Araújo e Costa (2007), e o chat educacional, apresentado em sua pesquisa anterior (BarbosaPaiva, 2010):

1 Mantivemos a denominação do gênero de chat usado pelos autores. 
Quadro 1. Comparação com relação à temática entre o chat aberto e o chat educacional

\begin{tabular}{|c|c|}
\hline $\begin{array}{c}\text { Chat Aberto (Araújo e Costa, 2007; Costa } \\
\text { (2005)) }\end{array}$ & Chat Educacional (BARBOSA-PAIVA, 2010) \\
\hline Temática & Temática \\
\hline $\begin{array}{l}\text { - A amizade (Buscam informações sobre o tra- } \\
\text { balho, hábitos e diversões preferidas pelo seu } \\
\text { interlocutor); } \\
\text { - } \text { A paquera }_{i} \\
\text { - } \text { A música; } \\
\text { - } \text { O erotismo. }\end{array}$ & $\begin{array}{l}\text { As temáticas dos chats educacionais inves- } \\
\text { tigados estão, intimamente, ligadas com as } \\
\text { funções dos chats educacionais investigados. } \\
\text { Nos corpora, observamos a presença de dois } \\
\text { grandes eixos temáticos: } \\
\text { - O primeiro eixo está relacionado às ques- } \\
\text { tões referentes, especificamente, ao curso } \\
\text { EPT; } \\
\text { - Já o segundo eixo está ligado à vida pessoal } \\
\text { dos participantes, sem que seja abordado } \\
\text { o curso EPT. }\end{array}$ \\
\hline
\end{tabular}

Fonte: Barbosa-Paiva, 2015, p. 182.

No Quadro 1, Barbosa-Paiva (2015) mostra de maneira comparativa dois gêneros distintos de chat: a referida por Araújo e Costa (2007) e Costa (2005) como "chat aberto" e o chat educacional. Segundo Barbosa-Paiva (2015, p. 183), "é notável a diferença entre esses dois gêneros", uma vez que as "temáticas do chat aberto parecem uma extensão de uma interação entre amigos e ou pessoas que estão se conhecendo, que conversam de diversos assuntos, bem como a procura de um paquera" (BARBOSA-PAIVA, 2015, p. 183). Já o chat educacional está voltado para questões relacionadas ao ensino, à educação. Cumpre acrescentar que embora haja o segundo eixo exposto, era o eixo primeiro que predominava no chat educacional (BARBOSA-PAIVA, 2015).

O Quadro 2 mostra também uma comparação feita por Barbosa-Paiva (2015) no que concerne à construção composicional entre o chat aberto ${ }^{2}$, investigado também por Araújo e Costa (2007), e o chat educacional, pesquisado em BarbosaPaiva (2010):

2 Mantivemos a denominação do gênero de chat usado por Araújo e Costa (2007). 
Quadro 2. Considerações com relação à construção composicional entre o chat aberto e o chat educacional

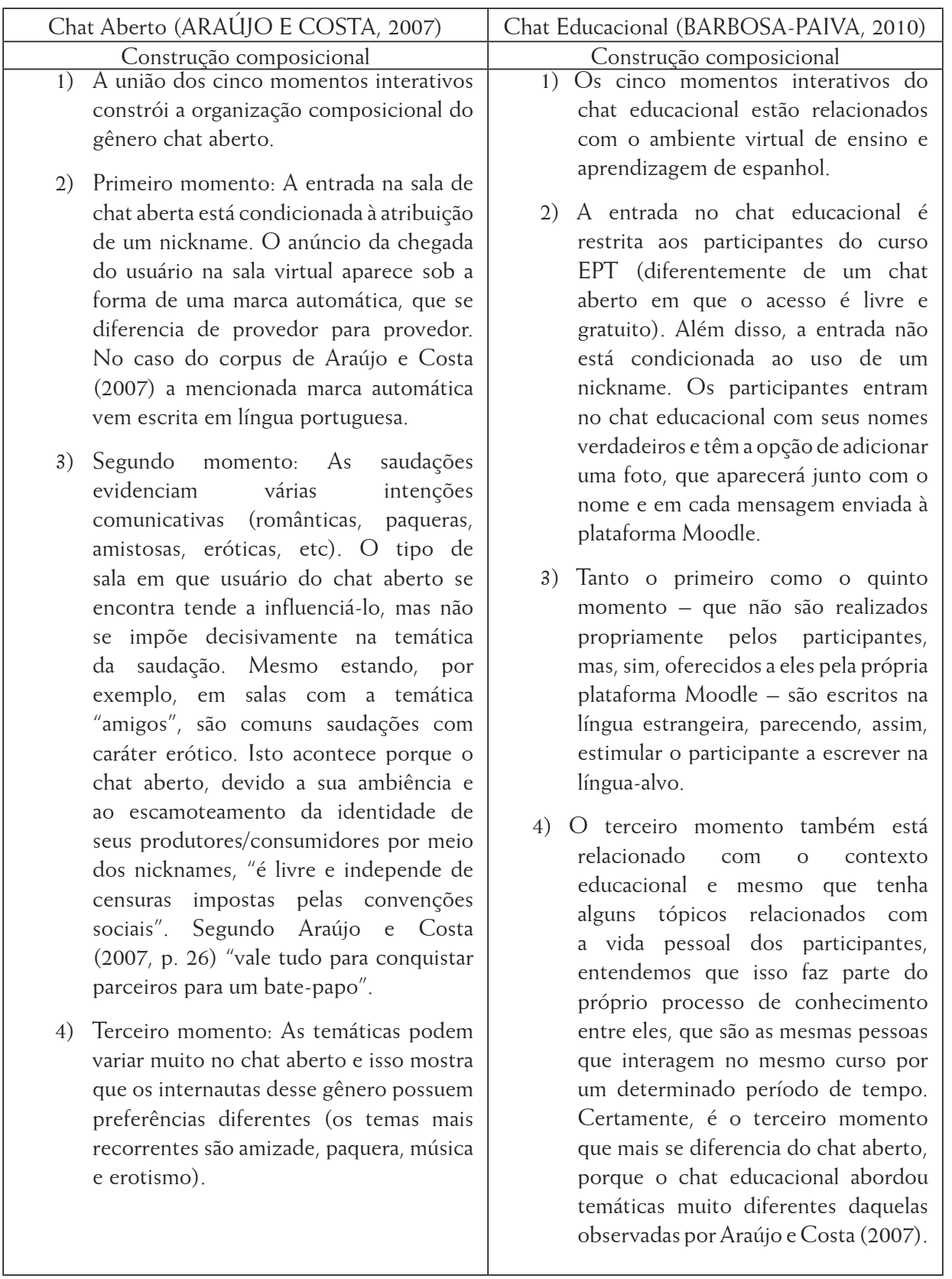


5) Quarto momento: As estratégias usadas para despedir-se dos usuários costumam variar e isso ocorre devido à diferença nas relações entre parceiros. Se os participantes se conhecem, as despedidas costumam ter mais polidez. Quando os parceiros não se conhecem e o contato começou no chat aberto, as despedidas assumem a função de dar prosseguimento à interação, quando surge o interesse de dar continuidade.

Nesse caso, os parceiros usam estratégias a fim de estreitar uma amizade virtual.

6) Quinto momento: A marca automática registrada pelo provedor anuncia a saída do internauta. Essa marca precisa a informação de que certo usuário saiu da sala de chat aberto. No caso do corpus de Araújo e Costa (2007), a referida marca automática de saída vem escrita em língua portuguesa.
Outro aspecto que distingue o chat educacional do chat aberto é a questão do uso de nicknames, que está ausente no chat educacional. Portanto, cada momento do chat educacional parece obedecer a uma particularidade específica do ambiente educacional.

Fonte: Barbosa-Paiva, 2015, p. 184.

Por fim, Barbosa-Paiva (2015) ressalta que os aspectos aqui apresentados contribuem para uma melhor compreensão do gênero discursivo chat educacional, um dos gêneros de chat, já que, conforme afirma Bakhtin (2003, p. 283), os gêneros "são diferentes em função da situação, da posição social e das relações pessoais de reciprocidade entre os participantes da comunicação". Barbosa-Paiva (2015) traz também a formulação de Rodrigues (2005, p. 167) - que reitera Bakhtin - quando afirma que "os gêneros, com seus propósitos discursivos, não são indiferentes às características da sua esfera, ou melhor, eles as 'mostram'" (RODRIGUES, 2005, p. 167), uma vez que, de acordo com Barbosa-Paiva (2015, p. 185), a função, o conteúdo temático e a construção composicional do chat educacional estão voltados, essencialmente, para um contexto educacional.

\subsection{0 conceito de gêneros discursivos}

Falamos por meio de gêneros do discurso, ou seja, "todos os nossos enunciados possuem formas relativamente estáveis e típicas de construção do todo" (BAKHTIN, 2003, p. 282). Dessa forma, dispomos de um rico repertório de gêneros de discursos tanto orais quanto escritos. Segundo Bakhtin (2003), os gêneros do discurso são dados às pessoas quase da mesma maneira que é dada a língua materna. Os falantes 
aprendem a moldar o seu discurso em formas de gênero. Para o autor, a comunicação discursiva seria quase impossível se os gêneros do discurso não existissem e se não os dominássemos ou se tivéssemos de criá-los pela primeira vez no processo do discurso ou se construíssemos livremente e pela primeira vez cada enunciado.

Com isso, a diversidade dos gêneros do discurso é imensa e é explicada pelo fato de que eles são diferentes em função da situação, da posição social e das relações pessoais de reciprocidade entre os participantes da comunicação (BAKHTIN, 2003). A vontade discursiva do falante se realiza na escolha de um determinado gênero de discurso e a intenção discursiva do falante, com toda a sua individualidade e subjetividade, é depois aplicada e adaptada ao gênero escolhido.

Existem gêneros padronizados e gêneros mais livres e mais criativos de comunicação discursiva oral (BAKHTIN, 2003). Bakhtin (2003) salienta que é preciso dominar bem os gêneros para usá-los livremente, já que muitas pessoas que dominam uma língua sentem total impotência em alguns campos da comunicação porque não dominam na prática as formas de gêneros de determinadas esferas. Assim, quanto melhor dominamos os gêneros, mais livremente os empregamos (BAKHTIN, 2003).

Bakhtin (2003, p. 264) diferencia gêneros discursivos primários (simples) e secundários (complexos), os quais aparecem em condições de um convívio cultural mais complexo e relativamente muito desenvolvido e organizado (predominantemente o escrito). No seu processo de formação, os gêneros secundários incorporam e reelaboram diversos gêneros primários (simples), que se formaram em condições da comunicação discursiva imediata. Para o autor (2003, p. 263), "esses gêneros primários, que integram os complexos, aí se transformam e adquirem um caráter especial: perdem o vínculo imediato com a realidade concreta e os enunciados reais alheios".

No que concerne à definição de gêneros do discurso, Bakhtin (2003, p. 261-262) defende que o conteúdo temático, o estilo e a construção composicional estão "indissoluvelmente ligados" no todo do enunciado. E esses elementos são determinados pela especificidade de um determinado campo da comunicação. Ele reconhece que cada enunciado é individual, mas que cada campo de uso da língua elabora seus "tipos relativamente estáveis" de enunciados, os quais ele denomina "gêneros do discurso" (BAKHTIN, 2003). Cumpre lembrar que, dentre esses três elementos que constituem o gênero, ressaltamos, em razão dos propósitos deste trabalho, a construção composicional e o conteúdo temático.

Fiorin (2006, p. 62) - retomando Bakhtin (2003) - explica os três elementos "bakhtinianos" na definição de gênero. Dessa maneira, Fiorin esclarece que o conteúdo 
temático "não é o assunto específico de um texto, mas é um domínio de sentido de que se ocupa o gênero". O autor exemplifica com as cartas de amor, que têm conteúdo temático das relações amorosas. Cada uma das cartas aborda um assunto específico. Na visão de Rodrigues (2005, p. 167), "todo gênero tem um conteúdo temático determinado: seu objeto discursivo e finalidade discursiva, sua orientação de sentido específica para com ele e os outros participantes da interação".

No que diz respeito à construção composicional, Fiorin (2006, p. 62) afirma que "é o modo de organizar o texto, de estruturá-lo". Já Grillo e Olímpio (2006), retomando também Bakhtin, esclarecem que "a forma composicional é a realização de uma forma arquitetônica por meio da organização de um material. [...] Essa organização se passa no nível da totalidade e da articulação das partes, dirigidas para uma finalidade" (p. 384). As autoras, ao sintetizarem a "forma composicional" - termo citado por elas, mas que equivalem, neste trabalho, por "construção composicional" -, afirmam que "a forma composicional encontra-se no nível da organização textual" (p. 386). Elas ressaltam que entre os três elementos caracterizadores do gênero mencionados por Bakhtin, a construção composicional é considerada como o elemento mais característico do gênero, tendo em vista a expressão "acima de tudo", supracitada em Bakhtin (2003).

Grillo e Olímpio (2006), ainda, destacam que, embora a forma composicional pertença ao enunciado, "ela não pode ser apreendida pelos métodos da lingüística da oração" (p. 386). Na visão de Rodrigues (2005, p. 167), a construção composicional consiste nos "procedimentos composicionais para a organização, disposição e acabamento da totalidade discursiva e da relação dos participantes da comunicação discursiva" (p. 167).

Podemos observar na citação de Bakhtin (2003) a seguir uma ênfase dada à construção composicional por meio do uso da expressão "acima de tudo".

O emprego da língua efetua-se em forma de enunciados (orais e escritos) concretos e únicos, proferidos pelos integrantes desse ou daquele campo da atividade humana. Esses enunciados refletem as condições específicas e as finalidades de cada referido campo não só por seu conteúdo (temático) e pelo estilo da linguagem, ou seja, pela seleção dos recursos lexicais, fraseológicos e gramaticais da língua mas, acima de tudo, por sua construção composicional (BAKHTIN, 2003, p. 261, itálico nosso)

É pertinente trazermos aqui a afirmação de Bakhtin (2003, p. p. 289) de que "todo enunciado é um elo na cadeia da comunicação discursiva". Assim, cada enunciado se caracteriza por um dado conteúdo semântico-objetal. A escolha tanto dos meios lingüísticos como dos gêneros de discurso é determinada pelas tarefas (pela ideia) do sujeito do discurso (ou autor) centradas no objeto e no sentido. É o 
primeiro momento do enunciado que determina as suas peculiaridades estilísticocomposicionais. O segundo elemento do enunciado, que lhe determina a composição e o estilo, é o elemento expressivo, ou seja, a relação subjetiva emocionalmente valorativa do falante com o conteúdo do objeto e do sentido do seu enunciado.

Apresentamos a seguir uma citação de Bakhtin na qual o autor argumenta que uma determinada função produz certos gêneros, que - conforme ele reitera e como já expomos -, se compõem do estilo, da temática e da composição "relativamente estáveis".

\begin{abstract}
Uma determinada função (científica, técnica, publicística, oficial, cotidiana) e determinadas condições de comunicação discursiva, específicas de cada campo, geram determinados gêneros, isto é, determinados tipos de enunciados estilísticos, temáticos e composicionais relativamente estáveis. O estilo é indissociável de determinadas unidades temáticas e - o que é de especial importância - de determinadas unidades composicionais: de determinados tipos de construção do conjunto, de tipos de acabamento, de tipos de relação do falante com outros participantes da comunicação discursiva - com os ouvintes, os leitores, os parceiros, o discurso do outro, etc (BAKHTIN, 2003, p. 266, itálico nosso)
\end{abstract}

Ainda, observamos a partir citação acima que Bakhtin defende que o estilo é "indissociável" da temática e da composição, a qual, ele entende que seria "tipos de construção do conjunto", entre outros. Fiorin (2006) aclara que o "ato estilístico é uma seleção de meios linguísticos. Estilo é, pois, uma seleção de certos meios lexicais, fraseológicos e gramaticais em função da imagem do interlocutor e de como se presume sua compreensão responsiva ativa do enunciado" (FIORIN, 2006, p. 62).

Na visão de Marcuschi (2008), os gêneros são entidades dinâmicas, históricas, sociais, situadas, comunicativas, orientadas para fins específicos, ligadas a determinadas comunidades discursivas, ligadas a domínios discursivos, recorrentes, estabilizadas em formatos mais ou menos claros. Devemos, assim, conceber os gêneros como entidades dinâmicas, como formas culturais e cognitivas de ação social corporificadas de maneira particular na linguagem, pois, segundo esclarece Marcuschi (2008), os gêneros não são modelos estanques ou estruturas rígidas.

Marcuschi (2008) entende que, na produção textual, os gêneros são "identidades poderosas", pois nos condicionam a escolhas, que não podem ser totalmente livres e nem aleatórias no que diz respeito ao léxico, ao grau de formalidade ou os temas. Ainda com relação aos gêneros, o autor (2008, p. 156) lembra que estes "limitam nossa ação na escrita", já que por um lado impõe restrições e padronizações, mas por outro lado "é um convite a escolhas, estilos, criatividade e variação". 
Conforme mencionamos, a fim de observar a construção composicional do chat educacional, partiremos dos cinco momentos interativos do chat aberto, estudados por Araújo e Costa (2007), que verificaram os seguintes momentos do chat aberto.

\subsection{A Organização Composicional do Chat Aberto}

A partir do modelo proposto por Araújo e Costa (2007), que a união dos cinco momentos interativos constrói a organização composicional do gênero chat aberto, definiremos esses cinco momentos de acordo com esses autores.

$1^{\circ}$ Momento: Marca automática do provedor, indicando que o internauta entrou na sala. A ambiência digital em que se realiza o gênero permite que os usuários sejam avisados aos outros participantes pelo próprio sistema por meio de uma marca automática. Esse aviso da "chegada" dos internautas constitui o primeiro contato que o participante tem nas salas de chat ou o seu primeiro momento interativo. Os internautas entram em uma sala de chat por meio de um nickname. "A autonomeação de um apelido virtual passa a ser uma condição sócio-técnica para garantir a participação do usuário na atividade de conversação aberta" (ARAỨJO e COSTA, 2007, p. 25).

$2^{\circ}$ Momento: Saudação inicial. Os usuários elaboram saudações para conquistar parceiro(s) para a comunicação (ARAÚJO e COSTA, 2007, p. 26). Araújo e Costa (2007) verificaram que as saudações evidenciaram várias intenções comunicativas (românticas, paqueras, amistosas, eróticas etc). Eles perceberam que o tipo de sala em que o internauta do chat aberto se encontra pode influenciá-lo, porém, não se impõe decisivamente na temática da saudação. Os autores observaram que, por exemplo, nas salas com a temática "amigos", é comum saudações com aspecto erótico. Nesse tipo de gênero de chat, há o uso de nickname e "vale tudo para conquistar parceiros para um bate-papo" (ARAÚJO e COSTA, 2007, p. 26).

$3^{\circ}$ Momento: Conversação. Araújo e Costa (2007, p. 27) afirmam que depois dos dois momentos interativos mencionados acima, geralmente a conversação se realiza. Parte dessas conversações ocorre entre usuários desconhecidos. É nesse momento da construção do texto que observamos os variados temas tratados nas salas de bate-papo. Os temas mais recorrentes foram a amizade, a paquera, a música e o erotismo. Segundo os autores, as temáticas podem variar muito no chat aberto. 
$4^{\circ}$ Momento: Despedida. Segundo Araújo e Costa (2007, p.28), para encerrar as conversações, os internautas vão anunciando a sua saída das salas de chat. Esses internautas usam estratégias para despedir-se dos parceiros virtuais.

$5^{\mathrm{o}}$ Momento: Marca automática do provedor, indicando que o internauta saiu da sala. O quinto momento que marca a organização textual do chat aberto é a marca automática registrada pelo próprio provedor, anunciando a saída do usuário da sala de bate-papo virtual (ARAÚJO e COSTA, 2007, p. 30).

\section{A CONSTRUÇÃO COMPOSICIONAL DO CHAT EDUCACIONAL}

No que concerne à construção composicional do corpus, verificamos que houve a presença de cinco momentos interativos, que serão apresentados a seguir:

* Primeiro momento: "Marca automática da plataforma Moodle, indicando que o participante entrou na sala"

Nos chats educacionais do curso EPT, a entrada do participante é anunciada, automaticamente, pela plataforma Moodle, por uma mensagem escrita em língua espanhola, sinalizando para os que já estão na sala virtual que chegou um novo participante (docente ou aluno). Essa mensagem constitui, portanto, o primeiro momento do chat educacional. A figura a seguir, retirada do curso do Marcos, ilustra esse momento:

Figura 1. Marca automática de entrada do participante no chat

14:19: Marcos Profe EPTM entró a la sala

14:23: Anise Eptm entró a la sala

$9^{a}$ sessão de chat educacional

O exemplo mostra que o docente Marcos e a aprendiz Amanda foram anunciados pelo próprio sistema da plataforma Moodle. Ainda na Figura 1, na posição onde aparecem os emoticons amarelos, havia a foto dos respectivos participantes, cuja foto foi substituída por questão de sigilo. Dessa forma, a foto acompanhava todas as mensagens escritas enviadas ao sistema pelo interagente. É importante destacar que tanto a foto como o nome verídico dos participantes são recursos relevantes para a identificação dos interagentes em um ambiente voltado ao 
ensino e aprendizagem de línguas, pois eles são vistos e tratados como pessoas com identidade real. Argumentamos que essas características particularizam o chat educacional, uma vez que o uso de nicknames ou apelidos virtuais é entendido como "um traço extremamente característico da linguagem dos grupos de chat síncronos" (CRYSTAL, 2002, p. 186), e que permite adquirir uma "nova personalidade" (SANMATÍN SÁEZ, 2007, p. 85), e, ainda, que "pode produzir uma curiosa separação no indivíduo entre sua identidade real e a identidade virtual gerada a partir de sua interação nos chats" (LÓPEZ GARCÍA, 2005, p. 105).

Continuando ainda a explicação da Figura 1, nela podemos observar ainda o horário de entrada e o nome (fictício) do participante, juntamente com a sigla "Eptm", seguida da mensagem "entró a la sala". Verificamos que a mensagem anunciando a entrada do docente expõe o seu papel no chat, o de professor, pela utilização da abreviação "profe".

Voltando ao esclarecimento do primeiro momento do chat educacional, argumentamos que fica muito claro para o interlocutor que o primeiro momento interativo não se trata da "voz" do interagente, mas, sim, a "voz" do outro (da plataforma), isto é, o enunciador do primeiro momento é o próprio sistema. Isto é evidenciado pelo verbo na terceira pessoa do singular "entró". É a partir da marca automática de ingresso do participante na sala de chat educacional que este "ganha voz" e está apto a escrever suas próprias mensagens e participar da conversação eletrônica. Ele já está "pronto" para começar a interagir com os demais que estão no chat.

\section{* Segundo momento: "Saudação inicial"}

Após a realização do primeiro momento do chat educacional exposto acima, temos, na sequência, as saudações entre os participantes - caracterizando, assim, o segundo momento do gênero chat educacional. É relevante destacar que, nesse gênero, o segundo momento parece ter duas finalidades a mais do que a simples "saudação": a) o professor dá as boas vindas aos alunos; e b) os participantes se apresentam. Argumentamos que essas duas finalidades revelam ser próprias do gênero chat educacional, já que seriam essas mesmas pessoas que se encontrariam por um determinado tempo. $\mathrm{O}$ exemplo a seguir mostra o primeiro contato entre professor-aluna:

Excerto 1 ( $10^{\mathrm{a}}$ sessão de chat educacional do Professor Marcos)

1. Ana: así que finalmente he conseguido conocerte

2. Ana: cómo estás? 
3. Ana: marcos?

4. Marcos: hola Ana!!!

5. Marcos: qué tal?!!

6. Marcos: bueno, bueno.... así que finalmente, ¿no?!

7. Marcos: iMuch gusto en conocerte!!

8. Ana: encantada!

No exemplo, os grifos nos turnos 7 e 8 mostram a saudação formal entre o professor Marcos e a aluna Ana. Fica evidente que é a primeira vez em que eles estão conversando via chat, apesar de esse diálogo pertencer à décima sessão de chat do curso EPT.

É preciso considerar que, no chat educacional, as boas-vindas do(a) professor(a) é um fato bastante recorrente no curso do Marcos e do da Irene à medida que chega um novo aluno. Nesse sentido, as boas vindas revelam ser peculiares do chat educacional, já que o docente procura acolher os alunos, como seria em uma sala de aula presencial. Ainda, temos que considerar que, no chat educacional, serão os mesmos participantes que se encontrarão na sala virtual diferindo de outro gênero de chat, em que dificilmente encontrarão os mesmos internautas. $\mathrm{O}$ excerto 2 a seguir mostra a professora desejando as boas-vindas às alunas:

Excerto 2 ( $2^{\mathrm{a}}$ sessão do curso da Irene)

1. Irene: $\underline{i B i e n v e n i d a s ~ a l ~ c h a t ! ~}$

2. Irene: ¿Tenéis alguna duda sobre el curso?

O próximo excerto mostra os participantes se apresentando:

Excerto 3 ( $6^{\text {a }}$ sessão do curso do professor Marcos)

1. Marcos: me gustaria que cada una de vosotras os presentara contando un poco su propio perfil...

2. Marcos: acadêmico,,.. gustos personales... cosas en comun que puedan tener. enfim...

3. Marcos: ups.. ACADÉMICOS... Y NO "ACADÊMICOS"!!!!

4. Amanda: Me llamo Amanda, vivo en Vista Alegre do Alto, estudio en el Faculdad São Luis

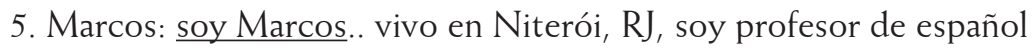

6. Amanda: Dónde viven ustedes? 
7. Marcos: otra cosa es el motivo de estar haciendo el curso....

8. Cássia: yo vivo en Bebedouro,sp. Soy estudiante de derecho y administración pública._

9. Amanda: Me encanta Bebedouro

10. Cássia: conoces Bebedouro?

11. Denise: Soy estudiante de "Letras" en la Unesp Araraquara, pero mí familia es de Ribeirao Preto. Hago espaõl en la universidad.

12. Amanda: Yo estoy hacendo el curso para adquirir mas conocimiento de la lengua

No exemplo 3, os grifos mostram que alguns participantes reiteram seus nomes na apresentação, apesar deles serem escritos, automaticamente, à medida que envia a mensagem à sala (Amanda: Me llamo Amanda, vivo en Vista Alegre do Alto, estudio en el Faculdad São Luis) e (Marcos: soy Marcos.. vivo en Niterói, RJ, soy profesor de español). No entanto, outras alunas "vão direto" para as informações pessoais (nome de cidade onde mora e profissão), como Cássia (turno 8), Denise (turno 11) e Amanda (turno 12).

Nesse sentido, diferentemente de uma apresentação face a face, em que os falantes falariam seus nomes, verificamos que isso pode não acontecer no chat educacional, pois o usuário é "apresentado" aos demais tanto pela mensagem automática do Moodle como pelo nome que acompanha cada mensagem enviada ao chat. Dessa forma, as fórmulas usadas pelos participantes "Me llamo + nome" e "Soy + nome" seriam dispensáveis no chat. O próximo excerto mostra que a saudação é um dos recursos usados pelo docente para "dar uma atenção individualizada" a cada aluno:

Excerto 4 (19 ${ }^{\mathrm{a}}$ sessão de chat educacional do curso do Marcos)

1. Patrícia: buenas tardes, Regina

2. Regina: buenas tardes

3. Patrícia: ya he recebido alguna respuesta del e-mail enviado?

4. Patrícia: pero yo no recebí nada

5. Patrícia: las agencias no me enviaran nada ... los intentos no fueran válidos...

6. Marcos Profe EPTM entró a la sala

7. Patrícia: Buenas tardes Marcos

8. Marcos: iHola Patrícia!

9. Marcos: iHola Regina!

10. Marcos: ibuenas tardes! 
Os grifos do excerto mostram que há saudações "específicas" entre os participantes, evidenciadas nos turnos 1, 7, 8, 9, cabendo ao vocativo o papel de direcionar a mensagem, e "saudações genéricas", reveladas nos turnos 2 e 10 . Entendemos que o tipo de "saudação específica" é relevante dentro do ambiente virtual de ensino, uma vez que há uma tentava de aproximação entre os participantes por tratá-los mais individualmente.

Um aspecto que parece estar relacionado com o chat educacional é que à medida que "chega" um novo participante, na sala virtual, este é saudado, de modo que a saudação é intercalada com o desenvolvimento da conversação. O exemplo a seguir traz evidências para essa análise:

Excerto $5\left(17^{\mathrm{a}}\right.$ sessão do curso da Irene)

1. Irene: Otro problema: Problema 2: CARÁCTER DISTINTO DE LOS PARTICIPANTES

2. Irene: [cada uno piensa y reacciona de una forma distinta...]

3. Elisa: Sí, los correos ayudan...

4. Irene: ¿qué hacer?

5. Amanda: Esto puede ser bueno desde haya respecto y buen senso

6. Paula Epti entró a la sala

7. Elisa: Buena pregunta...jejeje

8. Elisa: Hola Paula... [a]

9. Paula: Hola! Buenos días! [b]

10. Irene: ¿Más productivo negociar o ponerse de acuerdo con la mayoría?

11. Amanda: hola Paula, buenos dias! [c]_

12. Irene: [Hola, Paula, buenos días] [d]

13. Paula: Hola! [e]

14. Irene: [estamos en la terapía sobre las dificultades de los grupos, asómate también, Paula] [f]

O excerto 5 mostra que, no desenvolvimento do tópico discursivo da sessão ("dificuldades de trabalhar em grupo"), entra uma nova participante na sala virtual - Paula - e é saudada pelos colegas e pela professora, conforme os lugares indicados por [a], [c] e [d]. É interessante observar que a professora Irene usa os colchetes ( [ ] ), para escrever iniciar e encerrar a saudação, parecendo revelar que ela percebe um elemento inserido, dentro do tópico que estava em curso, no momento de sua produção textual, e decide marcá-las graficamente, concebendo a saudação, indicada por [d], um fato parentético por considerá-la como breve desvio do tópico 
discursivo. Vale, ainda, destacar que, em [f], a professora Irene procura interar Paula do tópico em curso, convidando-a a participar da discussão e entendendo como esse enunciado como parentetização/inserção parentética ${ }^{3}$, fato revelado, principalmente, pelas marcas concretas de sinais ortográficos de colchetes.

\section{Terceiro momento: "Conversação"}

Sucedendo os dois momentos expostos acima - Marca automática de entra e Saudação - normalmente, acontece a conversação propriamente dita, constituindo, dessa maneira, o terceiro momento interativo do chat educacional. Defendemos que se trata de um "mega-momento", pois nele pode haver, simultaneamente, diversos tópicos discursivos. É nesse "mega-momento" que a linguagem é elaborada com diversas estratégias de construção textual-interativas ${ }^{4}$ (Cf. BARBOSA-PAIVA, 2010, 2011, 2012, 2013, 2015, entre outros). Cumpre esclarecer que as temáticas ocorridas nesse terceiro momento serão discutidas na próxima seção. $\mathrm{O}$ excerto a seguir evidencia esse terceiro momento:

Excerto 6 ( $9^{\mathrm{a}}$ sessão de chat do curso do Marcos)

1. Marcos: $\underline{\dot{H} \text { Has conseguido leer mi mensaje?! }}$

2. Amanda: Muy bien

3. Marcos: sobre cambiar el mail que tienes en tu perfil de estudiante...

4. Amanda: Sí

5. Marcos: ċlo has conseguido cambiar?

6. Amanda: Yo cambié, cierto?

7. Marcos: espera un ratito... déjame averiguarlo... un minuto...

8. Marcos: iPERFECTO!!

9. Marcos: es importante que tengas bien el email en tu perfil, ya que todos los mensajes te llegan a partir del mismo...

10. Marcos: ¿qué tal con tus actividades y tareas? Como te va el curso?

O excerto permite observar que o professor Marcos inicia o tópico da sessão perguntando se a aluna conseguiu ler a mensagem dele a respeito da troca do email dela no perfil de estudante (turnos 1 e 3). Depois de desenvolver esse tópico até o turno 9, ele inicia outro no turno 10 no que concerne às atividades e tarefas do

\footnotetext{
3 Para uma observação mais detalhada do tema de inserção parentética em chat educacional, sugerimos os trabalhos de Barbosa-Paiva $(2011,2013,2015$, entre outros).

4 Entre as estratégias de construção textual-interativas podemos mencionar a repetição, a correção, a parentetização, a onomatopéia, os sinais de pontuação, entre outras.
} 
curso EPT (¿qué tal con tus actividades y tareas? Como te va el curso?), avançando o tópico na sequência.

No que concerne aos turnos no chat educacional analisado, observamos que há o predomínio por turnos longos, cuja escolha parece revelar que os participantes percebem a quantidade de estudantes na sala virtual que procuram tirar as suas dúvidas simultaneamente com o docente e decidem escrever turnos longos, levando à coerência e à compreensão da conversação, já que todos "falam de uma vez". Nesse sentido, a opção por turnos longos trata-se de uma das estratégias de construção textual nos chats ora analisados. Caso contrário, isto é, a presença de turnos menores, além de a mensagem ficar muito fragmentada, o que prejudicaria a inteligibilidade textual, os participantes teriam o desconforto de voltar a barra de rolagem do computador para "recuperar partes" da conversa, dificultando, inclusive, os docentes a responder as dúvidas dos alunos.

Consequentemente à estratégia de turnos longos, verificamos que a linguagem dos chats ora analisados revela ser "menos fragmentada", apesar de a característica da "fragmentação" estar presente em chats devido às condições de produção desse tipo de conversação (MAYANS (2002); LÓPEZ GARCÍA (2005), SANMARTÍN SÁEZ (2007), PÉREZ GRANDE (2004), entre outros). O excerto a seguir exemplifica a menor fragmentação da linguagem do chat educacional:

Excerto 7 ( $9^{\mathrm{a}}$ sessão do curso do Marcos)

1. Amanda: yo escribi correctamente; las respuestas automatica dicia que estaba incorrecto

2. Amanda: me falta práctica en escribir, en hablar, conocer los siginificados

3. Marcos: eso es verdad... el programa en el que basamos nuestro ejercicio no estaba aceptando algunas respuestas.. en este caso es, si no consigues contestar a los ejercicios, lo haces a través del Foro... o en forma de mensaje para mí, ¿̇vale?

4. Amanda: pero aquel ejercicio no era solo para practicarmos?

5. Amanda: como vás dibidir el grupo

6. Marcos: "para que practicáramos?"...

7. Marcos: justamente... como no son ejercicios que voy a corregir de cada uno de vosotros...

8. Marcos: si se presenta una dificultad en el ejercicio debes llevar esta dificultad al Foro..

9. Marcos: y comentarla con todos... a través del mismo Foro tendrás las respuestas a tus dudas..

10. Amanda: Comprendi 
11. Marcos: por eso es importante el uso del Foro...

12. Marcos: vale....; )

13. Marcos: y qué tal con la segunda semana...

14. Marcos: ¿́cómo te va?

No excerto, verificamos a presença de turnos longos (principalmente o turno 3) e, por conseguinte, uma linguagem menos fragmentada. Observamos que dos turnos (6 ao 9) e dos (11 à 14) são turnos realizados somente pelo professor Marcos, sem que haja alternância com turnos de outro interlocutor. Dessa forma, a mudança de um turno a outro parece revelar que ele procura escrever em cada turno uma "unidade de sentido". A análise evidencia que a "unidade de sentido" é que rege a escrita e, dessa maneira, a troca de turno do professor.

É significativo mencionar que os dados sugerem que as práticas conversacionais, a despeito de seu aparente "caos", são "condutas ordenadas, que se desenvolvem segundo alguns esquemas preestabelecidos e obedecem a algumas regras de procedimento" (KERBRAT-ORECCHIONI, 2006, p. 43).

Nesse sentido, nos chats educacionais, as regras que regem as interações verbais nas construções de "unidades formais", que são os turnos (KERBRATORECCHIONI, 2006), são as "unidades de sentido", entendendo-as como "unidade de sentido completo", sem que haja quebra de estrutura sintática entre sujeito, verbo e complemento. Houve raros casos em que o turno seguinte completava sintaticamente o turno anterior.

Ainda, sobre as características da linguagem do chat educacional, verificamos que os vocativos fazem parte do processo de formulação do chat. Sua presença na superfície textual é alta. Trata-se de uma das estratégias de formulação textual mais presentes, no chat, revelando, dessa forma, estratégia de construção textual desse tipo de texto. Os vocativos apresentaram um papel muito relevante na atividade conversacional dos participantes, uma vez que favorece a coerência e a organização textual. Além de criar um vínculo mais afetivo entre os participantes, os vocativos têm a função de direcionar a mensagem para o interlocutor "específico" dentre vários interlocutores "potenciais" dentro da sala de chat.

Argumentamos que o uso do vocativo, nos chats educacionais, sugere ser uma tentativa de suprir a ausência da linguagem não-verbal (os gestos, os movimentos corporais), pois a linguagem não-verbal está presente na conversação face a face, na qual um simples "olhar" desempenharia a função que o vocativo realiza no chat: direcionar a fala para o interlocutor determinado. $\mathrm{O}$ excerto a seguir corrobora a análise: 
Excerto 8 ( $2^{\mathrm{a}}$ sessão do curso do Marcos)

1. Regina: Marcos, podría hacer un de los ejercícios de Fecha de la carpeta? todas veces hago errado

2. Regina: Taís: Envié !

3. Cássia: Marcos, todas las actividades seran enviadas por el proprio sitio o tenemos que enviar alguna por e-mail?

4. Marcos: vale... Taís se fue Regina..

Os grifos dos vocativos mostram a recorrência dessa estratégia na construção textual do chat com a função de direcionar a mensagem ao interlocutor "específico". A presença do vocativo revela também uma atenção individual a cada participante. Cumpre mencionar, ainda, que nem sempre o vocativo, no corpus, recebe as marcas gráficas de delimitação do vocativo do texto escrito prototípico.

Acrescentamos que, durante a construção composicional do chat educacional, o par dialógico pergunta-resposta (P-R) teve uma importante função. Por meio dele, os participantes foram construindo o texto conversacional.

* Quarto momento: "Despedida"

Após conversarem sobre diversos assuntos, os participantes vão anunciando a sua saída do chat educacional no momento em que eles acham oportuno. Nesse sentido, o quarto momento do chat educacional é materializado por meio de estratégias dos participantes com a finalidade de encerrar sua participação na conversação.

É significativo mencionar que, embora haja variação com relação às estratégias usadas pelos aprendizes, o que nos chama a atenção é que o aluno, na maioria das vezes, não expõe o motivo pelo qual ele diz "precisar" sair da sala virtual. Com isso, percebemos que ele apresenta uma "certa autonomia" se comparado em situações de aula presencial, na qual o estudante, geralmente, não sai da sala no horário que quiser. O exemplo a seguir ilustra uma estratégia de um aluno que apresenta uma justificativa para a sua partida da sessão de chat educacional:

Excerto 9 ( $2^{\mathrm{a}}$ sessão de chat educacional do tutor Marcos)

1. Tadeu: profesor tngo que ir a la iglesia

2. Tadeu: digame que tengo que hacer ahora

3. Marcos: bueno... ahora mismo ya nada.... 
O grifo, no excerto, mostra uma estratégia de saída iniciada pelo aluno Tadeu, que afirma que precisa sair porque vai à igreja. $\mathrm{O}$ próximo excerto mostra a aluna Taís se despedindo sem expor o motivo da sua saída da sala:

Excerto 10 (22 $2^{\mathrm{a}}$ sessão do curso do Marcos)

1. Taís: bueno Marcos, tengo que irme ahora, agradezco su atención y muchas gracias, saludos desde Jaboticabal.

2. Taís: Buenas noches.

3. Marcos: vale Taís!!

Podemos observar, no turno 1, do excerto (10), a iniciativa da aluna Taís para finalizar sua participação no ambiente virtual. Notamos que a aprendiz não justifica o motivo de sua saída, apesar de parecer dar importância às regras de polidez ao acrescentar o agradecimento e as saudações ao professor Marcos, que aceita a tomada de decisão da aluna. Acrescentamos, ainda, que o diálogo evidencia uma despedida mais cortês e formal.

O próximo excerto mostra uma despedida, sugerindo ser menos formal, entre a professora Irene e as suas alunas:

Excerto 11 ( $20^{\mathrm{a}}$ sessão do curso da Irene)

1. Liliam: ahora tengo clases también

2. Liliam: besos : ) [a]

3. Irene: Beso y hablamos por los foros. [b]

4. Bia Epti entró a la sala

5. Liliam Epti salió de la sala

6. Irene: Hola, Bia. Volviste ...

7. Bia: bueno, sólo para me despedirme de ti porque mi ordenador no quiere trabajar hoy $_{\prime \prime \prime \prime}$ besos y un buen final de semana!!! [c]

8. Irene: Beso, Bia. Buen fin de fin de semana ... [d]

9. Bia: hasta mañana en verdad!!

10. Bia Epti salió de la sala

11. Irene: Me voy también. Buen trabajo a todos ... [e]

No excerto (11), nos lugares indicados por [a], [b], [c], [d] e [e], observamos que as participantes se despedem, de forma mais afetiva e íntima nos lugares indicados por [a], [b], [c], [d] e [e], diferentemente do excerto (10), em que se usa uma fórmula mais tradicional de despedida (no caso "mais formal"). Acrescentamos, 
ainda, que, com relação ao excerto (11), essa maneira de despedir-se parece uma tentativa de aproximação para suprir a ausência do contato físico, já que, conforme reiteramos, a conversa é mediada por computador.

* Quinto momento: "Marca automática da plataforma Moodle, indicando que o participante saiu da sala"

A marca automática de saída da plataforma Moodle constitui o quinto momento da composição textual do chat educacional. Nesse sentido, na sala virtual, os demais participantes são "avisados" pelo próprio sistema que determinado participante saiu da sala de chat. Semelhantemente ao primeiro momento interativo do chat educacional, a referida marca automática de saída aparece escrita, na língua espanhola, a expressão "nome do aluno", seguido da sigla "Eptm" + "salió de la sala".

É importante mencionar que nesse quinto momento - semelhantemente ao primeiro momento - não é a "voz" do aluno que é projetada na tela do computador, mas, sim, a da própria plataforma Moodle. A partir dessa marca automática de saída, todos os outros participantes que permaneceram na sala virtual têm a certeza de que o "outro" não está on-line, já que ele pode estar "presente na sala", mas não participar da conversação. O excerto a seguir ilustra o quinto momento interativo:

Excerto 12 (29a sessão do chat educacional do tutor Marcos)

1. Patrícia Eptm salió de la sala

2. Cássia Eptm salió de la sala

Um importante aspecto decorrente das análises dos dois cursos EPT é que a ordem de realização dos momentos não está relacionada com a sessão em si mesma, mas sim com os participantes, mais precisamente com a chegada dos participantes da sala virtual. Dessa maneira, não há uma ordem fixa de realização na sessão. Assim, o primeiro momento (marca automática de entrada na plataforma Moodle) não é, necessariamente, o primeiro que aparece e o mesmo acontece com os outros. Podemos afirmar que pode haver uma tendência em que os momentos apareçam na ordem: "Marca automática de entrada da plataforma Moodle", "Saudação inicial", "Conversação", "Despedida" e "Marca automática de saída da plataforma Moodle".

A análise do corpus revelou que os cinco momentos interativos podem vir "misturados", no desenvolvimento da sessão, de forma que possam ocorrer distintos momentos simultaneamente. Isso acontece devido a horários distintos da chegada de participantes ao ambiente, pois à medida que chega um novo usuário, a tendência é reaparecer todos os momentos novamente. Podemos afirmar, portanto, 
que há uma circularidade dos cinco momentos interativos no decorrer de uma sessão. Nesse sentido, haveria circularidade ou repetição dos momentos quando chegasse uma nova pessoa na sala. A figura 2, abaixo, ilustra essa circularidade nos chats educacionais analisados:

Figura 2. Circularidade dos momentos do chat educacional

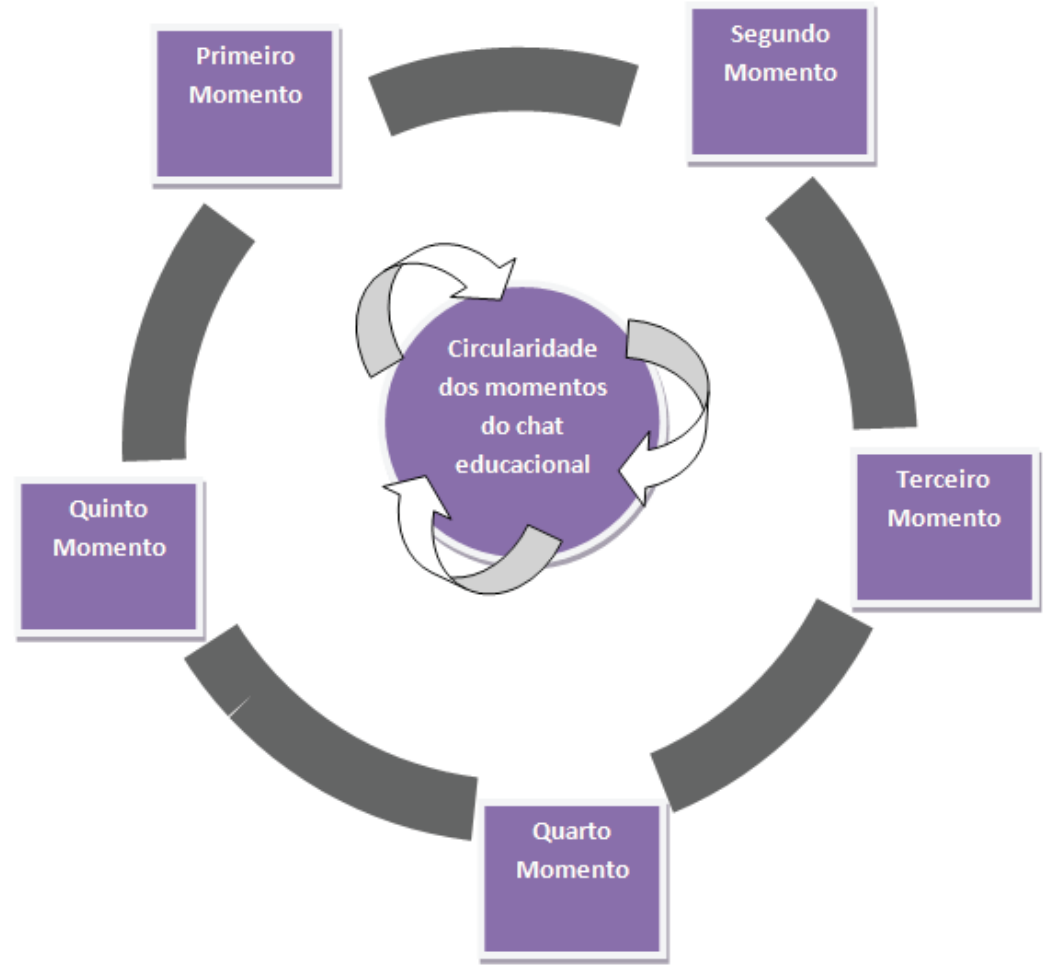

Fonte: Elaboração da autora (BARBOSA-PAIVA, 2010, p. 71)

\section{AS FUNÇÕES E A TEMÁTICA DOS CHATS EDUCACIONAIS NAS TURMAS DO EPT}

Com relação às funções desempenhadas pelo chat educacional, nos cursos EPT's, observamos que houve sessões em que havia a presença do(a) professor(a) e sessões em que ele(a) estava ausente, contanto apenas com a presença de alunos. 
Os quadros a seguir abordam as funções dos chats levando em conta as sessões com a presença e a ausência do docente.

\section{Quadro 3. Sessões de chat educacional em que havia a presença do docente} Sessões em que havia a presença do docente

a) Para a interação dos participantes na língua-alvo (espanhol);

b) Para saber o perfil e algumas informações pessoais do(a) aluno(a);

c) Para explicar a organização e estrutura do curso;

d) Para ajudar a resolver as atividades do curso (na maioria das vezes era o tutor que exercia esse papel);

e) Para tirar as dúvidas dos alunos;

f) Para saber como vão o curso EPT, os trabalhos, as atividades, as tarefas;

g) As alunas contam sobre o andamento das atividades, das tarefas;

h) Os/as estudantes querem saber como eles estão no curso EPT e seus rendimentos nele, suas "calificaciones";

i) Discussão sobre como organizar os alunos para a realização do trabalho finali

j) Para o(a) professor(a) saber o andamento dos trabalhos em grupo;

k) Para comentar sobre resultados de pesquisa de cada aluno;

1) Para refletir sobre trabalhar em grupo;

m) Para negociar o horário dos encontros via chat;

n) Para saber a opinião dos alunos acerca do projeto final de curso;

o) O docente lembrava aos alunos que ele(a) acrescentou alguma informação em outra "parte" do curso EPT (como, por exemplo, o "Fórum") sobre algo que os auxiliaria na realização do projeto final do curso.

Fonte: Barbosa-Paiva (2010, p. 73). 
Quadro 4. Sessões de chat educacional em que não havia a presença do docente

a) Ponto de encontro entre aluno-aluno para conversar sobre trabalhos em grupo;

b) Divisão de tarefas entre os participantes do grupo de trabalho;

c) Marcação de horário para um próximo encontro entre os componentes do grupo (sem o tutor) para mostrar o que cada um fiz;

d) Para "conhecer um pouco mais" (informações pessoais) sobre as colegas de grupo do trabalho final;

e) Para tirar alguma dúvida com a colega, tais como dúvida de vocabulário;

f) Quando um participante vê outro aprendiz on-line, na plataforma Moodle, um deles procura estabelecer uma conversa e fala sobre diversos assuntos (as atividades, o curso em si, a importância do curso EPT na vida pessoal, envio de uma mensagem assíncrona).

Fonte: Barbosa-Paiva (2010, p. 74).

Considerando os aspectos apresentados, nos quadros, acima, as duas formas de sessão (com a presença e com a ausência do docente) se mostraram muito produtivas para o curso EPT's. Pensando em um agrupamento que envolva todos os itens dos dois quadros, temos as seguintes funções das sessões de chat: i) para tratar questões relativas ao próprio curso e ao seu andamento; ii) para o conhecimento pessoal de cada participante, criando um vínculo afetivo entre eles, já que o curso foi ministrado à distância; e iii) para estabelecer a conversação na língua-alvo, uma vez que percebemos que os interagentes viam no chat uma oportunidade de interação real de uso da língua estrangeira.

No que concerne a essas duas maneiras de realização das sessões (presença e ausência do professor), podemos hierarquizar essas duas categorias, uma vez que as sessões que contavam com a presença do docente parecem ser compreendidas pelos participantes como "oficial", já que havia dia e hora marcada por eles para o encontro virtual. Já, nas sessões em que havia apenas alunos, observamos que poderia ser algum encontro agendado pelos aprendizes para discutirem assuntos referentes ao trabalho em grupo, do curso EPT, ou poderia ser, simplesmente, um "encontro casual" proporcionado pelo fato de alguns estarem, ao mesmo tempo, on-line na plataforma do curso. Entendemos, portanto, que cabe às sessões sem o docente uma função secundária em comparação com a outra categoria. 
No que diz respeito à análise da temática, no corpus, partimos dos apontamentos de Fiorin (2006) mencionados na parte teórica deste trabalho. Para o autor, "o conteúdo temático não é o assunto específico de um texto, mas é um domínio de sentido de que se ocupa o gênero" (FIORIN, 2006, p. 62). O autor exemplifica com as cartas de amor, que têm conteúdo temático de relações amorosas. Cada uma das cartas aborda um assunto específico.

Nesse sentido, as temáticas dos chats educacionais investigados parecem estar, intimamente, relacionadas com as suas funções dentro do ambiente virtual. No corpus, observamos a presença de dois grandes eixos temáticos, entendidos como "gerais", que são subdivididos por "subtemáticas". O primeiro grande eixo está denominado por "Temática 1 " e está relacionado às questões referentes, especificamente, ao curso EPT. Já o segundo grande eixo, nomeado por "Temática 2 ", está ligado à vida pessoal dos participantes, sem que seja abordado o curso EPT. Dessa maneira, colocamos abaixo esses dois eixos temáticos, que foram orientados pelos seguintes aspectos e/ou "subtemáticas":

$1^{\circ}$ ) Temática 1: Questões relacionadas especificamente ao curso EPT:

a) funcionamento e organização do curso EPT;

b realização de atividades ou do trabalho final em grupo (ver o andamento das atividades/ ou do trabalho final em grupo proposto pelo curso EPT);

c) eliminação de dúvidas relacionadas às atividades propostas pelo curso EPT,

d) reflexões e/ou opiniões/ esclarecimento sobre alguma dificuldade de realização de tarefas encontrada no curso sobre algum aspecto do curso EPT.

dúvidas sobre algum aspecto do curso.

$2^{\circ}$ ) Temática 2: Questões relacionadas à vida pessoal dos participantes, sem que seja abordado o curso EPT:

a) conhecimento entre os participantes

b) conhecimento sobre algum aspecto da sua vida real, alguma experiência pessoal não-relacionada ao curso, quando o participante relata algum aspecto da sua vida pessoal/real.

b) envolvimento pessoal entre os participantes.

O excerto a seguir ilustra a primeira temática abordada: 
Excerto 13 ( $6^{\mathrm{a}}$ sessão de chat do curso do Marcos)

1. Marcos: bueno Denise... ¿QQué te está pareciendo el curso?

2. Marcos: ¿̇Estás consiguiendo hacer las actividades?

3. Marcos: perdida en qué sentido Denise..

Os grifos do excerto mostram a preocupação do professor Marcos não somente no que diz respeito ao curso EPT (ou melhor, o que a aluna Denise está achando do EPT), mas também se a aprendiz está conseguindo realizar as atividades propostas pelo curso. O próximo excerto evidencia a segunda temática, isto é, o envolvimento pessoal entre os participantes:

Excerto 14 (19 $9^{\mathrm{a}}$ sessão de chat do curso da Irene)

1. Amanda: podemos ver con Irene y con los otros alumnos el día y la hora que todos o por lo menos la mayoría puede...

2. Livia: Si, es una óptima idea. Y tu, que estás haciendo en este atual momento de tu vida?

3. Amanda: estoy dando clases de Inglés y estudiando mucho para hacer un examén de nivel en español...

4. Amanda: sigo viviendo lejos de mi familia porque ingresé en un concurso del gobierno en la ciudad de Luiz Antonio ( cerquita de Ribeirão Preto)

5. Amanda: mi familia vive en Itápolis...

6. Livia: Fiqué impresonada con la cuantidad de personas que hacen este curso y que incluso también dan clases de español..

7. Amanda: qué te parece?

8. Livia: Para mi es muy rico porque pudo vivir más intensamente en esto ambiente...

9. Amanda: para mi también

10. Amanda: el idioma español y todo que está relacionado a él me encanta muchísimo

11. Livia: Hiciste algun grado, por exemplo, Letras...

12. Amanda: sí

13. Livia: Donde?

14. Amanda: Hice en Jaboticabal y después segui haciendo especializacíon en Critica Literária en La Unesp de Araraquara

15. Amanda: Y tú?

16. Livia: Y Nívea, es de Araraquara mismo?

17. Amanda: No sé. qué pena que no está aqui ahora...

18. Amanda: hicimos una bella amistad... 
19. Livia: Si, a mi me gustó mucho trabajar con vosotras..

20. Amanda: a mí también....

21. Livia: Podremos siguir en contato por e-mail...

22. Amanda: Estoy pasando un período dificil de mi vida y este curso, nuestra amistad... me calienta el corazón

23. Amanda: Sí, claro!

24. Amanda: Es un placer...

25. Livia: Creo que a mi también hará falta el curso..

A análise do excerto permite inferir que os participantes se "conheceram virtualmente" no curso EPT, uma vez que, como dissemos, o curso foi realizado totalmente a distância. Esse fato fica evidente pelas próprias trocas de informações pessoais entre as alunas. No entanto, reiteramos que alguns alunos já se conheciam presencialmente antes do curso EPT.

Ainda sobre as observações do excerto (14), podemos observar que as duas alunas, Amanda e Lívia, conversam sobre assuntos pessoais (turnos 3, 4 e 5), fazem comentários sobre o curso EPT (turnos 6, 7, 8, 9, 19 e 20), falando da importância do curso EPT na vida delas (turnos 8, 22 e 25) e a intenção de continuar tendo contato via e-mail (turno 21). Por fim, um aspecto que nos chamaram a atenção é o envolvimento pessoal que a aluna Amanda expõe, no turno 22, sobre a relevância do curso EPT e das amizades feitas dentro de um ambiente em que a interação é realizada por escrito e a distância.

\section{CONSIDERAÇÕES FINAIS}

Os cinco momentos analisados aparecem de forma muito clara. Eles compõem a organização textual do chat educacional e a combinação dos cinco momentos constrói a construção composicional do gênero chat educacional. No entanto, verificamos que, em algumas sessões, não ocorrem todos esses cinco momentos. Entendemos que isso possa ser explicado por problemas de queda de rede ou pelo fato de o usuário não sair da sala de chat, parecendo permanecer on-line. Nesse sentido, para que ocorra uma interação/conversa entre os participantes, via chat, não são necessários que se realizem, ao mesmo tempo, todos os cinco momentos, mas, sim, que desenvolva, principalmente, o terceiro momento ('conversação'), pois é nele que é estabelecida a conversação propriamente dita, com o desenvolvimento dos seus propósitos comunicativos. 
Observamos que o primeiro momento pode não aparecer em uma sessão. A nossa hipótese é que isto pareça estar relacionado com o fato de que a sessão iniciase em seguida da outra (no mesmo dia e com os mesmos participantes). Assim, para os participantes que já haviam participado da sessão ocorrida no mesmo dia e que permaneceram on-line no Moodle, observamos que não havia o registro da marca do primeiro momento na sessão que se iniciava. Percebemos que houve sessões que foram interrompidas por problemas técnicos e por isso a justificativa de iniciar outra na sequência. $\mathrm{O}$ quinto momento também pode não aparecer e nossa hipótese é que o internauta permanece on-line no Moodle. Portanto, excetuando-se o terceiro momento, os demais não são obrigatórios para que ocorra a interação via chat.

Entendemos que os momentos são etapas ou fases ou, ainda, regras de uma conversação de maneira que "saudar", "conversar" (sobre um tópico) e "despedir-se" são momentos ou etapas que também podem ser encontrados em uma conversação face a face. O que há de inovação nos chats educacionais investigados com relação a um texto conversacional face a face são os momentos interativos oferecidos pelo próprio sistema da plataforma Moodle: as marcas automáticas de entrada e as de saída do usuário na sala virtual, que constituem, respectivamente, o primeiro e o quinto momento.

O turno constitui-se na principal articulação composicional do chat educacional. O conjunto de turnos constrói o todo da organização do chat. Entendemos por "turno", no chat, "cada intervenção por escrito enviada ao interlocutor por meio da tecla enter". O que marca o caráter conversacional e interativo da construção composicional do chat. Em resumo, a construção composicional do chat educacional incorpora e reflete as condições específicas e as finalidades da esfera educacional do gênero chat educacional, que se define como uma conversação institucional.

Apesar de a análise do corpus revelar os cinco momentos interativos do chat aberto, estudado por Araújo e Costa (2007), observamos que, no chat educacional, esses momentos estão relacionados com o ambiente virtual de ensino e aprendizagem de espanhol. Assim, o tanto o primeiro como o quinto momento - que não são realizados propriamente pelos participantes, mas, sim, oferecidos a eles pela própria plataforma Moodle - são escritos na língua estrangeira, parecendo, assim, a estimular o participante a escrever na língua-alvo. $O$ terceiro momento também está relacionado com o contexto educacional e mesmo que tenha alguns tópicos relacionados com a vida pessoal dos participantes, entendemos que isso faz parte do próprio processo de conhecimento entre os participantes, que são as mesmas pessoas que se interagem no mesmo curso por um determinado período de tempo. Certamente, é o terceiro momento que mais se diferencia do chat aberto, 
porque o chat educacional abordou temáticas muito diferentes daquelas observadas por Araújo e Costa (2007). Outro aspecto que distingue o chat educacional do chat aberto é a questão do uso de nicknames, que está ausente no chat educacional. Portanto, cada momento do chat educacional parece obedecer a uma particularidade específica do ambiente educacional.

\section{REFERÊNCIAS BIBLIOGRÁFICAS}

ARAÚJO, J. C. (2006). Os chats: uma constelação de gêneros na Internet. 341f. Tese (Doutorado em Linguística). Programa de Pós-Graduação em Linguística da Universidade Federal do Ceará. (UFC), Fortaleza.

ARAúJO, J. C.; COSTA, N. (2007). Momentos Interativos de um Chat Aberto: A Composição do Gênero. In ARAÚJJ, J. C. (Org.) Internet \& Ensino: novos gêneros, outros desafios. Rio de Janeiro: Lucerna.

BAKHTIN, M. (2003). Os gêneros do discurso. In BAKTHIN, M. Estética da criação verbal. 4. Ed. Tradução do russo Paulo Bezarra. São Paulo: Martins Fontes.

BARBOSA-PAIVA, C. L. (2013). Parenthetical como una modalidad de inserción en chat educacional en la enseñanza de español como lengua extranjera (ELE). In: Beatriz Blecua; Sara Borrell; Berta Crous; Fermín Sierra. (Org.). Plurilinguismo y enseñanza de ELE en contextos multiculturales. 1. ed. Girona: ASELE (Asociación de Español como Lengua Extranjera), p. 145-152. Disponível: http://cvc.cervantes.es/ensenanza/ biblioteca_ele/asele/pdf/23/23 0014.pdf. Acesso: 21 de agosto de 2015.

BARBOSA-PAIVA, C. L. (2012). A correção como procedimento de reformulação em chat educacional escrito em espanhol por brasileiros: tipos de operacionalização e marcas. Trabalbos em Linguística Aplicada, Campinas, v. 51, n. 1, p. 119-151, jun. 2012. Disponível em <http://www.scielo.br/scielo.php?script=sci_arttext\&pid=S0103$18132012000100007 \& \operatorname{lng}=p t \& n r m=i s o>$. Acesso em 18 ago. 2015. http://dx.doi. org/10.1590/S0103-18132012000100007.

BARBOSA-PAIVA, C. L. (2011). A parentetização: estratégia de construção textualinterativa do chat educacional. Revista Brasileira de Linguística Aplicada, Belo Horizonte, v. 11, n. 3, p. 773-798, 2011. Disponível em <http://www.scielo.br/scielo. php? script $=$ sci_arttext\&pid $=$ S1984-63982011000300009\&lng $=$ pt\&nrm $=$ iso $>$. Acesso em 18 ago. 2015. http://dx.doi.org/10.1590/S1984-63982011000300009. 
BARBOSA-PAIVA, C. L. (2010). Estratégias de construção textual do chat escrito em espanbol como língua estrangeira. 238 f. Dissertação (Mestrado em Linguística e Língua Portuguesa) - Faculdade de Ciências e Letras, Universidade Estadual Paulista Júlio de Mesquita Filho, Araraquara.

BARBOSA-PAIVA, C. L. (2015). Proposta teórico-metodológica para análise de inserções parentéticas em chat educacional no ensino de lingua espanbola. Salamanca: Ediciones Universidad de Salamanca.

CRYSTAL, D. (2002). El lenguaje e Internet. Traducción española de Pedro Tena. Madrid: Cambrigde University Press.

CRYSTAL, D. (2005). A revolução da linguagem. Tradução de Ricardo Quintana; consultoria, Yonne Leite. Rio de Janeiro: Jorge Zahar.

FIORIN, J. L. (2006). Introdução ao pensamento de Bakbtin. São Paulo: Ática.

GRILlO, S. V. de C.; OLÍMPIO, A. M. (2006). Gêneros do discurso e ensino. In: Filologia e Lingüística Portuguesa, n. 8, São Paulo: Universidade de São Paulo, FFLCH/USP, p. 379-390.

KERBRAT-ORECCHIONI, C. (2006). Análise da conversação: princípios e métodos. Tradução de Carlos Piovezani Filho. São Paulo: Parábola Editorial.

LÓPEZ GARCÍA, G. (2005). Modelos de comunicación en Internet. Valencia: Tirant Lo Blanch.

MARCUSCHI, L. A. (2008). Gêneros textuais no ensino de língua. In MARCUSCHI, L. A. Produção textual, análise de gêneros e compreensão. São Paulo: Parábola Editorial.

MARCUSCHI, L. A. (2005). Gêneros textuais emergentes no contexto da tecnologia digital. MARCUSCHI, L. A.; XAVIER, A. C. (Orgs.). Hipertexto e gêneros digitais: novas formas de construção do sentido. 2. Ed. Rio de Janeiro: Lucerna.

MAYANS, J. (2002). Género chat. O cómo la etnografía puso un pie en el ciberespacio. 1. ed. Barcelona: Gedisa.

RODRIGUES, R. H. (2005). Os gêneros do discurso na perspectiva dialógica da linguagem: a abordagem de Bakhtin. In: MEURER, J. L.; ADAIR, B.; MOTTA-ROTH, D. (Orgs). Gêneros: teorias, métodos, debates. São Paulo: Parábola Editorial, p. 152-183. 
PÉREZ GRANDE, M. D. (2004). Comunicación e interacción mediadas tecnológicamente. In: GARCÍA DEL DUJO, A; MARTÍN GARCÍA; PÉREZ GRANDE, M. Procesos de Formación on line. Salamanca: Amarú Ediciones.

SANMARTíN SÁEZ, J. (2007). El chat. La conversación tecnológica. Madrid: Arco Libros.

Recebido: 05/02/2015

Aceito: 23/08/2015 